\title{
COTAS NAS UNIVERSIDADES PÚBLICAS
}

SANTOS, Jocélio Teles dos (org.). Cotas nas universidades: análises dos processos de decisão. Salvador: Centro de Estudos Afro-Orientais da UFBA, 2012. 284p.

SANTOS, Jocélio Teles dos (org.). O impacto das cotas nas universidades brasileiras (2004-2012). Salvador: Centro de Estudos Afro-Orientais da UFBA, 2013. 278p.

Houve um tempo de fazer. Nesse tempo, havia apenas a experiência conhecida do que se passara nos Estados Unidos, poucas referências aos casos da Índia e da África do Sul, e experiências pouco estudadas mas bem sucedidas de políticas de reserva de mercado implementadas entre nós desde o primeiro governo Vargas. As ações afirmativas para garantir o acesso de estudantes negros às universidades brasileiras foram feitas, portanto, a partir dessas poucas reflexões prévias, num complexo jogo de alianças e negociações políticas entre reitores, congregações universitárias e movimentos sociais, sob a vigilância ativa da opinião pública e de muitos intelectuais públicos. Ao final, prevaleceram as cotas sobre outras formas de inclusão, como os bônus.

Hoje é tempo de refletir sobre essa história e escrevê-la. Estando garantida por uma decisão do $\mathrm{Su}$ premo Tribunal Federal, podemos fazê-lo sem o compromisso ativista de quando a defendíamos. Os livros Cotas nas universidades: análises dos processos de decisão e $O$ impacto das cotas nas Universidades públicas brasileiras (2004-2012) têm o mérito de trazer para o crivo da reflexão um conjunto expressivo de experiências de adoção e implementação de cotas em universidades federais e estaduais em diferentes partes do país, com exceção da região Norte. Em termos temporais, pode-se afirmar que relatam processos de implementação de cotas desde as primeiras iniciativas, em 2004, até a Lei Federal no 12.711, de 2013, que "unificou" e deu homogeneidade ao sistema de reserva de vagas nas universidades federais.

No primeiro livro, encontramos estudos, ricos em detalhes, sobre como ocorreu o processo político que levou à decisão por reserva de vagas em onze estabelecimentos de ensino superior. Como foram os primeiros debates? Quem eram os atores políticos diretamente envolvidos? Quais respostas institucionais foram apresentadas pela burocracia universitária? Quais técnicas e retóricas de convencimento político foram usadas pelos atores engajados na mobilização em favor das cotas? Como se formou a reação política contra tal proposta no âmbito interno e externo à universidade? Essas e tantas outras questões dão viva- 
cidade aos artigos que compõem a coletânea, organizada por Jocélio Teles dos Santos. Nesse sentido, os registros micro-históricos entrelaçam-se às memórias dos autores, que, na maior parte dos casos, foram também atores no processo de decisão que levou às formas particulares e diversificadas de implementação das cotas.

Do processo político, dois pontos parecem particularmente bem detalhados por todos os autores: a mobilização favorável à implementação das cotas e as reações à adoção de tal sistema. Embora não sejam temas novos na literatura acadêmica, lidos em conjunto é possível identificar padrões recorrentes nas experiências minuciosamente descritas no primeiro livro.

Desse modo, verifica-se a presença marcante de três tipos de agentes políticos: os ativistas oriundos da sociedade civil; os professores e pesquisadores universitários; e os gestores públicos da instituição de ensino superior. Os primeiros agentes, muitas vezes, em forma de movimentos sociais (movimento negro, cursinhos pré-vestibulares, lideranças e organizações indígenas, pastorais religiosas) funcionaram como grupos de pressão sobre as instituições universitárias em várias etapas do processo - da abertura do debate, passando pela aprovação dos projetos, à implementação propriamente dita. Isso ocorreu tanto em casos em que a política se deu por meio de leis estaduais, como naque- les gestados no interior da burocracia universitária, que, aliás, correspondem à maioria das experiências de ações afirmativas no Brasil.

Assim como os ativistas, muitas vezes, externos ao ambiente universitário, os agentes "internos" aos círculos acadêmicos foram centrais na articulação do processo que levou à adoção das cotas e à forma pela qual essa política configurou-se no sistema universitário. Docentes e pesquisadores atuaram em comissões para implementação de ações afirmativas, apresentaram justificativas técnicas e normativas de defesa das cotas e elaboraram projetos que tramitavam na burocracia institucional, além de se fazerem presentes em audiências públicas nas universidades, nos debates na imprensa e nas reuniões de conselhos universitários. Por fim, eles mediaram os conflitos e a relação entre o movimento social e a burocracia estatal. Exemplos marcantes que revelam tal atuação podem ser apreendidos nos artigos que tratam das universidades federais de Goiás (UFG), Maranhão (UFMA) e Santa Catarina (UFSC), além das estaduais de Mato Grosso do Sul (UEMS) e de Santa Cruz (UESC).

Por sua vez, em nenhum caso analisado, descartou-se a relevância de agentes públicos. Muitas instituições tiveram seus projetos adiados por semestres, justamente porque não havia "boa vontade" para colocar em votação o projeto de cotas. Os artigos revelam a relevância de gestores públicos favoráveis às 
políticas de inclusão para o andamento dos processos no interior da burocracia universitária. Dignos de nota foram a participação ativa de pró-reitores, como na Universidade Estadual do Mato Grosso do Sul (UEMS) e na Universidade Federal de São Paulo (UNIFESP); e o envolvimento direto de reitores, a exemplo da Universidade Federal da Bahia (UFBA) e da Universidade da Estadual de Londrina (UEL).

Por fim, registre-se a presença e a participação institucional dos núcleos de estudos afro-brasileiros (NEABs), que promoveram debates e ofereceram dados e estudos sobre desigualdades de acesso ao Ensino Superior; dos intelectuais e das autoridades convidados para palestras; dos políticos (vereadores, deputados, secretários); das associações de classe e estudantis; além dos órgãos estatais relacionados com a igualdade racial. A presença desses apoiadores não foi uma regra geral nos casos analisados, entretanto, pelo menos um deles esteve presente no processo político de adoção das cotas.

No que toca às reações, em geral, os autores afirmam que, embora houvesse grande resistência à reserva de vagas nas universidades, essa oposição, na maioria das vezes, se mostrou camuflada, ou seja, não se apresentou de forma direta e pública nos fóruns criados para discutir esse tema. Ao que parece, as resistências discente e docente revelaram-se de forma enviesada e indireta. Dois artigos são felizes em registrar a forma pela qual se deu a reação às cotas em duas instituições. Antonio F. Beraldo e Eduardo Magrone, que discorreram sobre a Universidade Federal de Juiz de Fora (UFJF), mostram a indignação e o receio dos alunos frente à possibilidade de existência de cotas nas universidades nas quais pretendiam entrar ou nas quais já estavam matriculados. De outro lado, os relatos presentes no capítulo sobre o processo de decisão na UFBA, escrito por Jocélio T. dos Santos e Delcele M. Queiroz, revelam os argumentos e as alternativas encontradas por professores para expressar sua revolta frente à possibilidade de adoção de cotas naquela universidade.

No que se refere ao conteúdo das reações, os argumentos listados ao longo do livro Cotas nas Universidades: análises dos processos de decisão não diferem daqueles que já tinham sido elaborados e analisados desde a década de 1990, quando o tema das ações afirmativas eram quase um delírio nos debates públicos do Brasil. A oposição às cotas foi mais intensa ao se discutir a reserva de vagas para negros, do que para estudantes de escolas públicas. Não sendo exagero supor que isso talvez explique o modelo de ingresso diferenciado que combinou "classe" e "raça", ou seja, beneficiou estudantes negros originários de escolas públicas ou simplesmente egressos do sistema púbico de ensino.

Vale a pena relembrar os tópicos do discurso de objeção às cotas: 1) o 
modelo de miscigenação do país impediria a identificação de quem é negro; 2) as cotas sacrificariam o mérito; 3) a má formação de egressos de escolas públicas poderia comprometer a qualidade da universidade; 4) com o tempo, as cotas azedariam as relações raciais, criando ou aumentando o racismo; 5) o sistema de cotas seria inconstitucional. Ao ler os capítulos do livro, é notável a recorrência e persistência desses temas ao longo do tempo, bem como sua difusão em diferentes partes do país. Nesse sentido, os argumentos de oposição não apresentaram particularidades relevantes, compondo, assim, uma retórica modelar. Saliente-se o caráter defensivo e de reação daqueles que se opuseram às cotas, em contraste com o discurso reformista e propositivo daqueles que lutavam para introduzi-las no sistema universitário brasileiro.

Com processos políticos repletos de impasses, idas e vindas, altos e baixos, aprovaram-se pouco a pouco, nos conselhos universitários, todas as ações voltadas para a inclusão de segmentos sociais negativamente privilegiados na sociedade. Os programas são, de fato, particulares, e refletem os debates, a correlação de forças dos atores políticos envolvidos e as características das suas respectivas universidades. Mas, embora haja essa diversidade de formas (critérios e estratégias de seleção, perfil de beneficiários, percentual de vagas), se o leitor estiver atento poderá perceber que muitas são as semelhanças nos sistemas de inclusão adotados pelas instituições analisadas. A começar pelo fato de que todas decidiram por limitar um número de vagas que combinassem critérios étnico-raciais com socioeconômicos, ou seja, as cotas destinaram-se a estudantes, negros ou não, oriundos de escolas públicas (as duas únicas instituições analisadas que apresentaram reservas de vagas para negros, independentemente da origem escolar, foram a UFSC e a UFSM). Somaram-se a esse perfil geral os indígenas, que foram grupos preferenciais em universidades como a UEMS, UFS (Universidade Federal de Sergipe), UFSC, Unifesp e a UFRGS (Universidade Federal do Rio Grande do Sul), dentre outras.

Do ponto de vista dos resultados, expostos no livro $O$ impacto das cotas nas universidades brasileiras (2004-2012), os autores são unânimes em afirmar que as cotas foram eficientes para aumentar a proporção de estudantes de escolas públicas nas universidades, especialmente nos cursos mais tradicionais, de maior prestígio ou de elevada concorrência. O que parece óbvio, dada a forma de seleção. Mas a maior presença de negros não esteve garantida, posto que, em boa parte das universidades, as vagas destinadas aos pretos e pardos não eram completamente preenchidas, por diversas razões, dentre elas, a baixa demanda, deficiências e viés no sistema de seleção, retenção no pro- 
cesso seletivo por não atingir nota de corte, ou mesmo a opção pessoal dos concorrentes negros pelo sistema universal. Do mesmo modo, alguns autores apresentam sérias preocupações com os estudantes indígenas, especialmente no que toca a sua inserção nos cursos, apontando que o sistema precisaria se aperfeiçoar para atender ao perfil desse grupo peculiar. Como os analistas salientam, a língua oficial do Brasil não é exatamente a língua materna dos descendentes dos povos nativos de nosso país. Uma reflexão atenta para as particularidades da inserção indígena no sistema universitário é encontrada, por exemplo, no texto de Marcelo H. R. Tragtenberg, Alexandra C. Boing, Antonio F. Boing e Antonella M. I. Tassinari, que analisam a experiência da Universidade Federal de Santa Catarina.

No caso dos estudantes negros, o grau de eficiência do programa de cotas também é ponto nevrálgico na discussão. Um dos problemas principais refere-se ao volume de inserção desses estudantes, que, de modo geral, não chega a atingir as expectativas do programa. Dito de outra maneira: a demanda é menor do que as vagas ofertadas. Além disso, dados de algumas universidades indicam que o desempenho escolar (medido na maioria das vezes por médias ponderadas) é menor para negros, especialmente quando os cursos ou disciplinas apresentam grau elevado de dificuldades para o conjunto da turma, ou seja, quando cotistas e não cotistas têm grande probabilidade de tirar notas baixas ou até serem reprovados. Isso é particularmente notável em cursos da área de Ciências Exatas, ou em disciplinas como as de Cálculo.

Por sua vez, os analistas flagraram a perseverança no comportamento institucional dos estudantes cotistas negros. Maria Nilza da Silva e Jairo Q. Pacheco mostram, ao analisar o caso da Universidade Estadual de Londrina, onde estudantes negros apresentaram baixo índice de evasão, mesmo tendo maiores dificuldades de aproveitamento em certos cursos. Além do mais, os especialistas na análise das cotas sugerem que o acompanhamento acadêmico e os auxílios financeiros, bem como a assistência estudantil são medidas eficazes para reduzir as possíveis desigualdades educacionais dos estudantes oriundos de escolas públicas, como sublinham Karl Monsma, João V. S. Souza e Fernanda O. da Silva ao interpretarem dados qualitativos referentes às experiências de estudantes negros da Universidade Federal do Rio Grande do Sul.

Como o leitor pode inferir, a leitura dessas duas coletâneas é obrigatória para os jovens pesquisadores que se interessam pelo tema das desigualdades e políticas de inclusão no ensino superior, e não apenas para os historiadores. Embora falando do passado, nas citadas coletâneas podem ser encontradas tanto informações e análises qualificadas 
sobre processos que ainda estão a transcorrer, como indicam novos problemas de investigação a exigir investidas mais densas. Como as pesquisas brasileiras sobre as ações afirmativas têm sido geralmente feitas por estudos de caso, cuja generalização de resultados sempre produz algum viés, a leitura dos dois livros oferece a rica oportunidade de visualizar, de uma só vez, um quadro di- versificado de experiências. Carecemos, agora, de interpretações mais abrangentes que consigam oferecer um quadro analítico mais amplo, seja em termos comparativos, ou mesmo para explicar o significado dessas políticas no plano nacional, levando em consideração tanto as políticas de cotas, como as demais modalidades de ações afirmativas adotadas no país até 2012 .

Antonio Sérgio A. Guimarães asguima@usp.br Universidade de São Paulo

Flavia M. Rios flaviamrios@yahoo.com.br Universidade de São Paulo 